\title{
MATERIAL PARAMETER OF RUBBER GLOVE VULCANIZED USING COMBINED INFRARED AND HOT-AIR HEATING
}

\author{
Tipapon Khamdaeng, Numpon Panyoyai and Thanasit Wongsiriamnuay
}

Faculty of Engineering and Agro-Industry, Maejo University, Chiang Mai, Thailand

Received 2013-12-11; Revised 2013-12-13; Accepted 2014-02-08

\begin{abstract}
Vulcanization is an important chemical-thermal process in production of rubber products resulting in change of material properties, increased elasticity and strength. In general, Young's modulus is used as an indicator of elastic deformation at loading configuration. However, rubber is not truly elastic and a single parameter is insufficient to describe the whole deformation contributed by microstructure of rubber network. Therefore, we present the material parameters concerning the mechanical interaction of rubber constituents. In this study, tensile force and elongation were measured to analyze the rubber deformation. In order to describe the deformation behavior of the combined infrared and hot-air vulcanized rubber glove, the material properties, stress and stretch, were therefore presented. The stress-stretch relationships of the vulcanized rubber gloves were established based on previously well-known hyperelastic material model and their material parameters were determined using a parameter estimation technique. In conclusion, the stressstretch relationships of the combined infrared and hot-air vulcanized rubber glove can be successfully established with our optimized material parameters; the magnitudes of rubber modulus $\left(\mathrm{C}_{\mathrm{R}}\right)$ and locking stretch $\left(\lambda_{\mathrm{L}}\right)$ were in a range of $0.041-0.079 \mathrm{MPa}$ and 10.27-70.12, respectively. Furthermore, the resulting material parameters can be properly used to indicate the micro structural deformation.
\end{abstract}

Keywords: Constitutive Law, 8-Chain Network Model, Infrared Ray, Vulcanized Rubber

\section{INTRODUCTION}

Vulcanization has been known as an important chemical-thermal process of the rubber production which has been discovered by Charles Goodyear in 1843. Sulfur and additives were added in the process of the production of the rubber products in order to provide more elasticity and prevent degradation by heat. Several heating processes were incorporated into vulcanization methods, for example, hot air, microwave and infrared (Bideau et al., 2009; Zhang et al., 2004; Clark and Sutton, 1996). The vulcanization methods and optimized heating processes of the rubber gloves have been investigated (Makuuchi et al., 1990). However, the nonhomogenous temperature on the rubber glove during the process causes the non-homogeneous material in the final product. The rubber region where has the low elasticity and strength will damage before the other regions. From this reason, the combined heating, including convection and radiation heat transfer, should be considered as the effective heating process to improve the temperature distribution as well as to determine the new optimized parameters of the vulcanization.

Therefore, in this study, the combined infrared and hot-air heating process was used. Since the infrared can potentially penetrate into the material with their shorter wavelengths, the heat and mass transfer inside material is subjected to the emission. Infrared combined with hot-air heating will provide the complex phenomena than infrared or hot-air heating only (Dongbang and

Corresponding Author: Tipapon Khamdaeng, Faculty of Engineering and Agro-Industry, Maejo University, Chiang Mai, Thailand Tel: +66-5387-5869-71, Fax: +66-5387-8113 
Matthujak, 2013; Lakhal et al., 2009). Furthermore, the infrared heater is not only easy to set with another system due to the less space using and uncomplicated setting but also quickly responses to temperature controlling. The heating parameters that expectedly affect the temperature distribution of the present vulcanized rubber glove are temperature, vulcanized duration and distance between infrared heater and rubber glove.

To verify the material standard of the final rubber product, the rubber must be performed on the mechanical testing. The general quantitative characterization of a linear elastic material is known as Young's modulus. However, the rubbery material has a network structure to enable a non-linear deformation (Boyce and Arruda, 2000). The contribution of this network structure results in the stress-strain response. Therefore, the stiffness of rubbery material should be determined from the slope change of the stress-strain curve. Several constitutive models have been proposed based on undergoing large strain, using a large deformation theory (Ali et al., 2010; Sasso et al., 2008; Guo and Sluys, 2006; Marckmann and Verron, 2006; Ogden et al., 2004; Arruda and Boyce, 1993). The well-established hyperelastic models were approached by using assumptions of both statistical and continuum mechanics. The statistical mechanics model, such as the Langevin (Arruda and Boyce) 8-chain model, provides suitably estimation of the large strain response with a few material parameters concerning the microstructure of the network, also called microstructural model. The invariant-based continuum mechanics model represents the phenomenological response which the invariants can be implied to microstructural deformation. However, in order to establish the continuum mechanics model, many constants and data sets must be required (Boyce and Arruda, 2000).

In this study, we propose to establish the stress-strain relationships of the combined infrared and hot-air vulcanized rubber glove using the Langevin (Arruda and Boyce) 8-chain model and to optimize their material parameters, which are rubber modulus $\left(C_{R}\right)$ and locking stretch $\left(\lambda_{\mathrm{L}}\right)$, at any vulcanized condition.

\section{MATERIALS AND METHODS}

\subsection{Experimental Setup}

Rubber gloves were formed using the medium size of hand mold. The Pre-Vulcanized Rubber latex (PVHA) was prepared in a container. The mold was heated up at $80^{\circ} \mathrm{C}$ for 2-3 min and was dipped into coagulation, preparing from $10 \%$ calcium chloride. The mold was removed and was heated again. After that, the mold was dipped into the rubber latex for $10 \mathrm{sec}$ and was removed. A thin layer of the rubber latex covering the hand mold was vertically placed in the cabinet vulcanized rubber dryer and was heated using the combined infrared and hot-air. The cabinet vulcanized rubber dryer construction will be briefly detailed as follow.

As illustrated in Fig. 1A, the cabinet vulcanized rubber dryer was made of sheet metal at the outside and stainless steel at inside, to prevent the erosion from the evaporated acid moisture and has insulations in between these metals. The hand mold stand was made of stainless steel and was fixed at the cabinet center. Control system includes temperature controller, temperature sensor, on/off blower controller and LED to present the operating conditions. The dryer consists of two types of heater, i.e., two $1000 \mathrm{~W}$ infrared and two $1500 \mathrm{~W}$ finned heaters. Both infrared and finned heaters were controlled by temperature sensors. Two infrared heaters were set in the cabinet on the opposite side which one was fixed and another one was attached to the rail in order to adjust the distance between the heater and the rubber glove. Circulated hot air with average velocity of $0.5 \mathrm{~m} / \mathrm{s}$ was flowed pass the finned heaters via the inlet channel on the upper side of the cabinet. The hot air flow direction is shown in Fig. 1B.

\subsection{Mechanical Model}

The rubber gloves were tested on standard of methods for vulcanized rubber and thermoplastic elastomers tension (ASTM D 412). The tensile load set of $10 \mathrm{kN}$ was applied on the dumbbell-shaped test sample with gauge length of $33 \mathrm{~mm}$ (Type C). At break point, the overall tensile load was determined. The tensile stress was then calculated based on the Cauchy's stress theorem. The hyperelastic constitutive equation in the axial direction can be written in term of strain energy function (Humphrey and Delange, 2004) as shown in Equation (1):

$$
\sigma_{\mathrm{zz}}=\frac{1}{\operatorname{det} \mathrm{F}} \Lambda \frac{\partial \mathrm{W}}{\partial \Lambda}
$$

\section{Where:}

$\sigma_{\mathrm{zz}}=$ Cauchy stress in the axial direction

$\mathrm{F}=$ Deformation gradient tensor and det $\mathrm{F}$ was equal to unity since the rubber deformation was assumed to be incompressible

$\Lambda=$ Stretch ratio in the axial direction

$\mathrm{W}=$ The strain energy function 


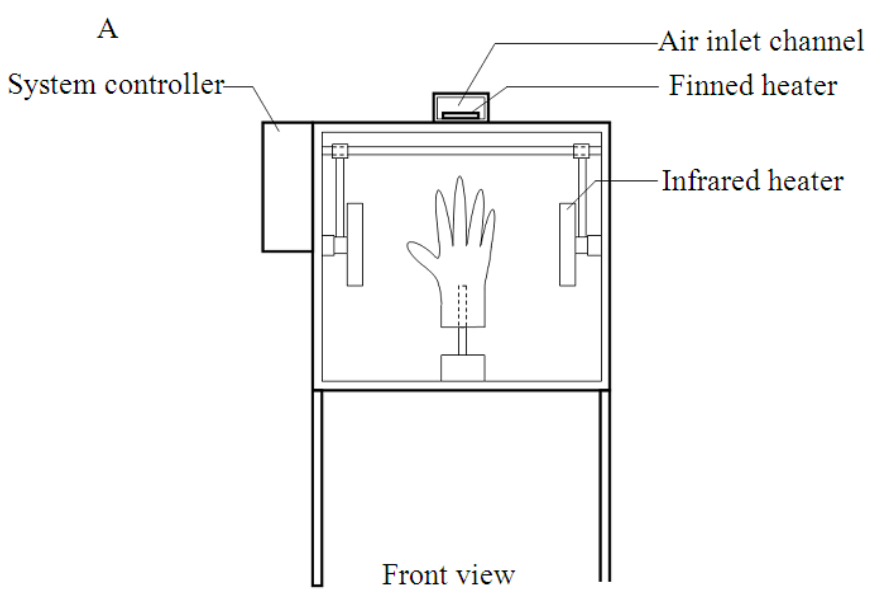

B

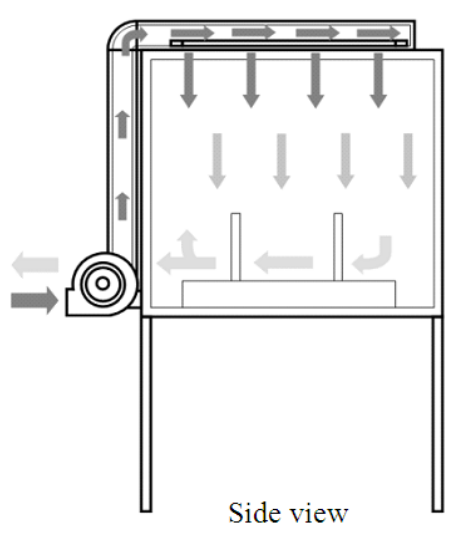

Fig. 1. The cabinet vulcanized rubber dryer; (A) the main component consists of system controller, finned heater, infrared heater and air inlet channel. (B) Diagram of hot air flow. Dark and light gray arrows respectively represent the direction of hot air flow with higher inlet and lower outlet temperatures

In this study, the stress-strain relationships of the vulcanized rubber glove were fit using the Langevin (Arruda and Boyce) 8-chain model (Arruda and Boyce, 1993) which is expressed as Equation (2):

$$
\mathrm{W}=\mathrm{NkT} \sqrt{\mathrm{n}}\left[\beta_{\text {chain }} \lambda_{\text {chain }}+\sqrt{\mathrm{n}} \ln \left(\frac{\beta_{\text {chain }}}{\sinh \beta_{\text {chain }}}\right)\right]
$$

\section{Where:}

$\mathrm{N}=$ The number of chains per unit volume

$\mathrm{k}=$ Boltzmann's constant 1

$\mathrm{T}=$ Temperature

$\mathrm{n}=$ The number of individual segment of the molecule length

$\beta_{\text {chain }}=$ The inverse Langevin function that is given by Equation (3):

$$
\mathrm{L}\left(\beta_{\text {chain }}\right)=\operatorname{coth}\left(\beta_{\text {chain }}\right)-\frac{1}{\beta_{\text {chain }}},
$$

$$
\beta_{\text {chain }}=\mathrm{L}^{-1}\left(\frac{\lambda_{\text {chain }}}{\sqrt{\mathrm{n}}}\right)
$$

where, $\lambda_{\text {chain }}$ is stretch on each chain in the structure which is defined as the root mean square of the stretch in three orthogonal axes in the Cartesian coordinates Equation (4):

$$
\lambda_{\text {chain }}=\left[\frac{1}{3}\left(\frac{1}{\sqrt{\Lambda}^{2}}+\frac{1}{\sqrt{\Lambda}^{2}}+\Lambda^{2}\right)\right]^{\frac{1}{2}}
$$


The two material parameters obtained from the Langevin (Arruda and Boyce) 8-chain model were rubber modulus and locking stretch defined as $\mathrm{C}_{\mathrm{R}}=$ NkTand $\lambda_{\mathrm{L}}=\sqrt{\mathrm{n}}$, respectively.

\subsection{Parameter Estimation}

The material parameters of the constitutive equation were calculated using a parameter estimation technique. The minimization of the objective function was required in order to estimate the best-fit values of the material parameters. In this study, the minimizing function of mean square error of the axial stresses at any configuration was determined. The expression is given by Equation (5):

$$
\chi^{2}=\sum_{\mathrm{k}=1}^{\mathrm{n}}\left(\sigma_{\mathrm{zz}}-\sigma_{\mathrm{zz}}^{\exp }\right)_{\mathrm{k}}^{2}
$$

Where:

$\mathrm{k}=$ The $\mathrm{k}^{\text {th }}$ of $\mathrm{n}$ data points

$\sigma_{\mathrm{zz}}^{\exp }=$ The Cauchy stress in the axial direction calculated directly from the uniaxial loading test which was assumed to be uniform in stress distribution which can be evaluated by Equation (6):

$$
\sigma_{\mathrm{zz}}^{\exp }=\Lambda \frac{\mathrm{f}}{\mathrm{A}_{\mathrm{o}}}
$$

Where:

$\mathrm{f}=$ Applied load

$\mathrm{A}_{\mathrm{o}}=$ Undeformed area

\section{RESULTS}

The temperature distributions of the vulcanized rubber gloves are shown in Fig. 2. At the distance between infrared heater and rubber glove of $5 \mathrm{~cm}, 10 \mathrm{~cm}$ and $15 \mathrm{~cm}$, the average standard deviation of the temperature were respectively found to be equal to $5.20^{\circ} \mathrm{C}, \quad 8.00^{\circ} \mathrm{C}$ and $3.66^{\circ} \mathrm{C}$. The temperature distributions of rubber gloves vulcanized at the distance between infrared heater and rubber glove of $15 \mathrm{~cm}$ were uniform than those of the other distances.

The Cauchy stresses for each vulcanized rubber glove were determined using Equation (1)-(4) at 300\% strain and at break point. The Langevin (Arruda and Boyce) 8chain model was applied to describe the stress-stretch behavior and was fit with the 18 uniaxial data sets. The
Cauchy stress-stretch relationships of the vulcanized rubber gloves were established at different conditions of temperature, vulcanized duration and distance between infrared heater and rubber glove as shown in Fig. 3. The material parameters were estimated using a parameter estimation technique as given by Equation (5)-(6). The optimized parameters were precisely obtained with the minimizing function of mean square error of the Cauchy stresses. The optimized parameters of the vulcanized rubber gloves at each vulcanized condition are shown in Table $\mathbf{1 .}$

The Cauchy stress distributions of 6 vulcanized conditions that provided a desired large deformation, corresponding to the Cauchy stress-stretch relationships of Fig. 3, were plotted along with the deformed dumbbell-shaped test samples (Fig. 4). Therefore, the capture images of the Cauchy stress distributions at break point can be observed. The magnitudes of the Cauchy stresses and stretches of vulcanized rubber glove were in a range of 4.49-7.35 $\mathrm{MPa}$ and 9.17-11.54, respectively.

\section{DISCUSSION}

This study aims to establish the Cauchy stress-stretch relationships of the vulcanized rubber gloves. Both nominal stress and stretch were experimentally measured in order to determine the stress-stretch relationship. Using the hyperelastic constitutive equation in the axial direction as shown in Equation (1), the Cauchy stress can be written in term of nominal stress and stretch.

The 27 vulcanized conditions were considered but only 18 vulcanized conditions that obtained wellproduced rubber gloves were used to estimate the material parameters and only 6 vulcanized conditions provided a desired large deformation, i.e., (i) $80^{\circ} \mathrm{C}, 5$ $\mathrm{cm}$ and $5 \mathrm{~min}$, (ii) $80^{\circ} \mathrm{C}, 10 \mathrm{~cm}$ and $5 \mathrm{~min}$, (iii) $80^{\circ} \mathrm{C}$, $10 \mathrm{~cm}$ and $10 \mathrm{~min}$, (iv) $80^{\circ} \mathrm{C}, 10 \mathrm{~cm}$ and $15 \mathrm{~min},(\mathrm{v})$ $80^{\circ} \mathrm{C}, 15 \mathrm{~cm}$ and $10 \mathrm{~min}$ and (vi) $80^{\circ} \mathrm{C}, 15 \mathrm{~cm}$ and 15 min. Since the Langevin (Arruda and Boyce) 8-chain model was clearly captured the effective behavior of a complicated network response of deformed rubber (Boyce and Arruda, 2000), this model was then applied to our study. We found that, the 18 uniaxial data sets can be very well fit with the Langevin (Arruda and Boyce) 8-chain model and our optimized material parameters (Table 1). Therefore, the Cauchy stressstretch relationship can be used to represent an interesting deformation behavior that was directly related to the deformed rubber glove. 
Tipapon Khamdaeng et al. / American Journal of Applied Sciences 11 (4): 648-655, 2014

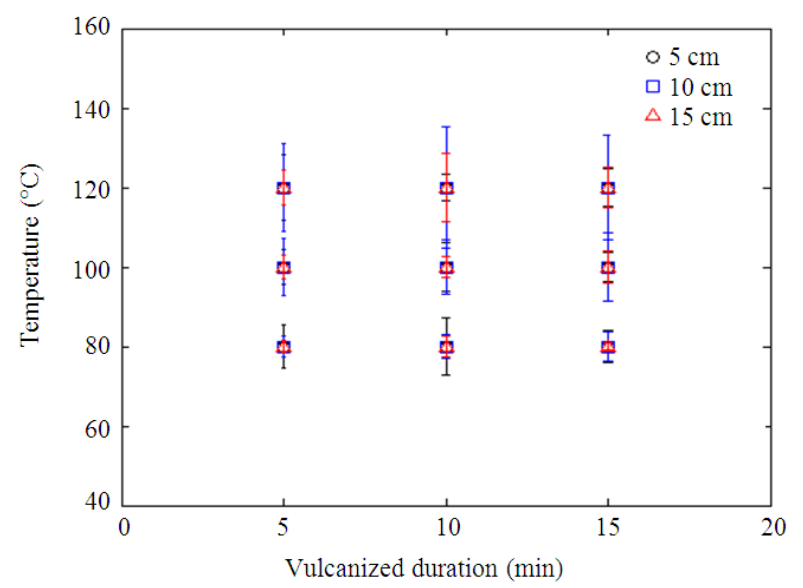

Fig. 2. Temperature distributions on the vulcanized rubber gloves at the distance between infrared heater and rubber glove of $5 \mathrm{~cm}$, $10 \mathrm{~cm}$ and $15 \mathrm{~cm}$ with different temperatures and vulcanized durations
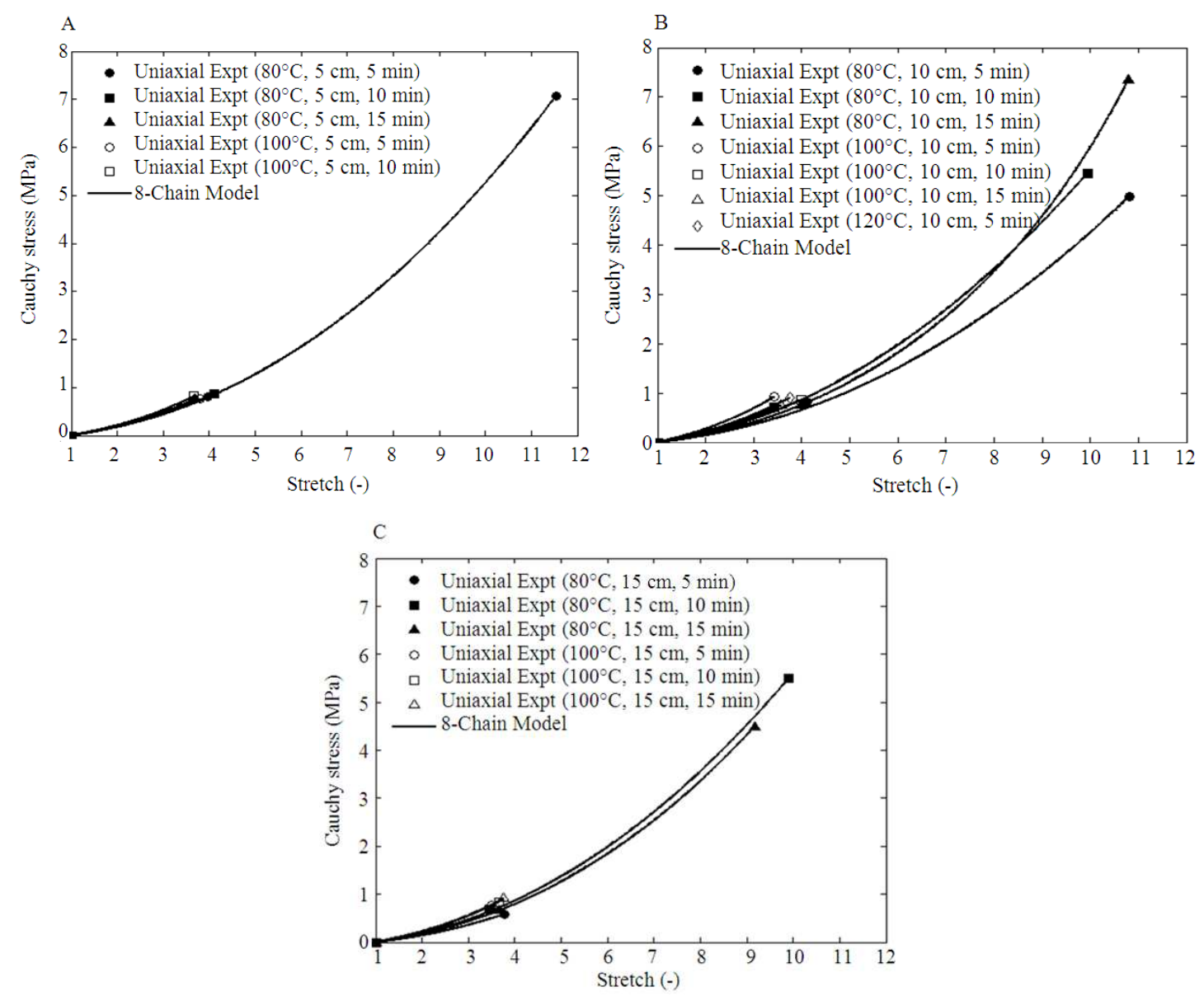

Fig. 3. Comparison of the Cauchy stress-stretch relationship of the Langevin (Arruda and Boyce) 8-chain model to the uniaxial loading test of the vulcanized rubber gloves at the distance between infrared heater and rubber glove of (A) $5 \mathrm{~cm}$ (B) 10 $\mathrm{cm}$ and $(\mathrm{C}) 15 \mathrm{~cm}$ with different temperatures and vulcanized durations 

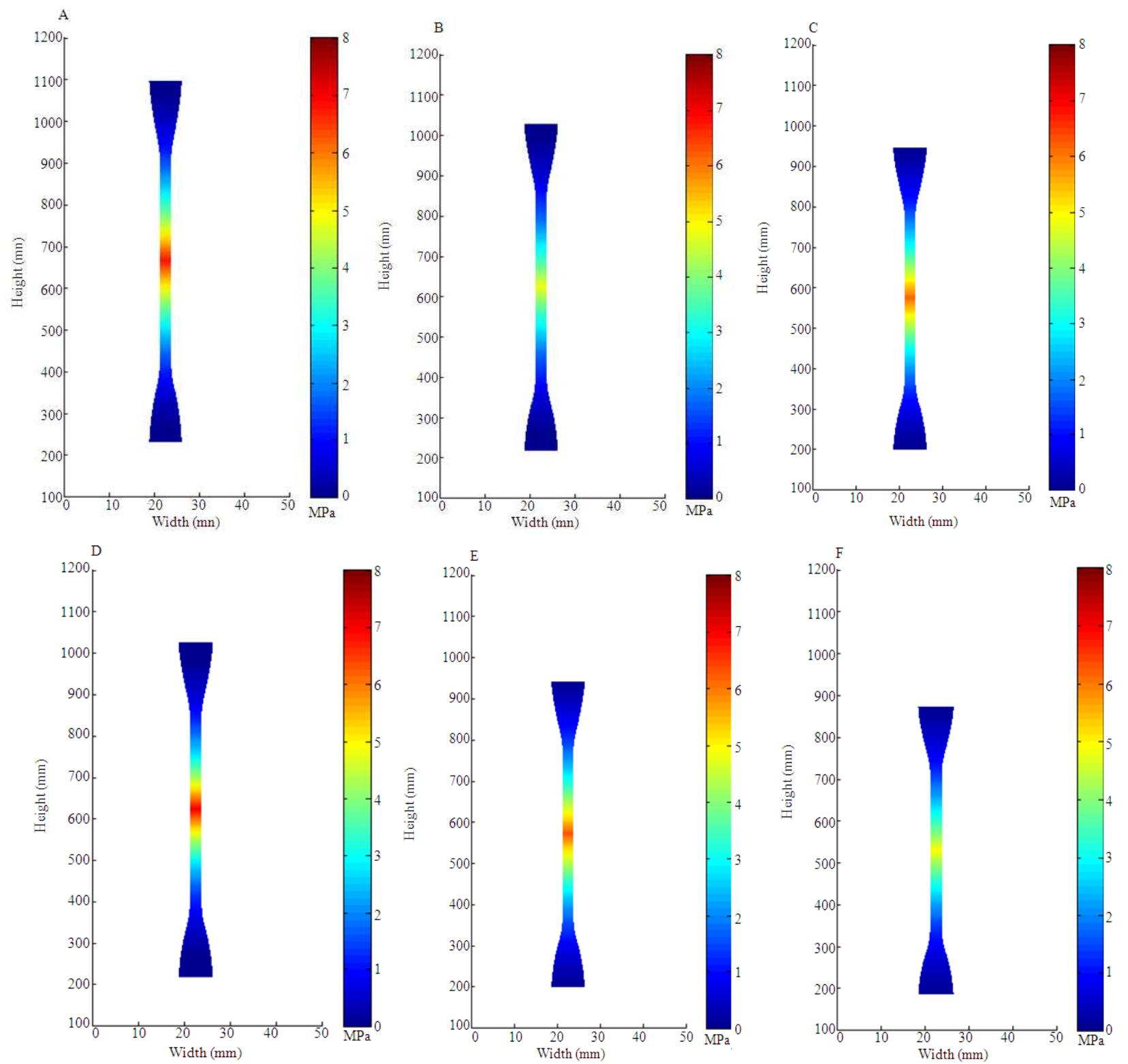

Fig. 4. The Cauchy stress distributions of deformed dumbbell-shaped test samples with six proper vulcanized conditions; (A) $80^{\circ} \mathrm{C}, 5 \mathrm{~cm}, 5 \mathrm{~min}(\mathrm{~B}) 80^{\circ} \mathrm{C}, 10 \mathrm{~cm}, 5 \mathrm{~min}(\mathrm{C}) 80^{\circ} \mathrm{C}, 10 \mathrm{~cm}, 10 \mathrm{~min}(\mathrm{D}) 80^{\circ} \mathrm{C}, 10 \mathrm{~cm}, 15 \mathrm{~min}(\mathrm{E}) 80^{\circ} \mathrm{C}, 15 \mathrm{~cm}, 10 \mathrm{~min}(\mathrm{~F})$ $80^{\circ} \mathrm{C}, 15 \mathrm{~cm}, 15 \mathrm{~min}$

The material parameters of the Langevin (Arruda and Boyce) 8-chain model were rubber modulus $\left(C_{R}\right)$ and locking stretch $\left(\lambda_{L}\right)$. The magnitudes of $C_{R}$ and $\lambda_{L}$ were in a range of 0.041-0.079 $\mathrm{MPa}$ and 10.27-70.12, respectively. It can be noticed that $C_{R}$ and $\lambda_{L}$ were respectively smaller and greater (in approximately one magnitude of order) than previous reports (Clausen et al.,
2010; Qi and Boyce, 2004; Arruda and Boyce, 1993) since the rubber glove using present vulcanized heating process characterized smaller in material stiffness. In addition, the combined infrared and hotair vulcanized rubber glove was found to be not significantly greater ( $\mathrm{p}$-value $>0.001$ ) in stiffness than the infrared vulcanized rubber glove. 
Tipapon Khamdaeng et al. / American Journal of Applied Sciences 11 (4): 648-655, 2014

Table 1. The optimized parameters of the vulcanized rubber gloves from the different vulcanized conditions

\begin{tabular}{|c|c|c|c|c|c|}
\hline \multirow[b]{2}{*}{ Temperature $\left({ }^{\circ} \mathrm{C}\right)$} & \multirow[b]{2}{*}{ Distance $(\mathrm{cm})$} & \multirow[b]{2}{*}{ Duration (min) } & \multicolumn{2}{|c|}{ Optimized parameters } & \multirow[b]{2}{*}{$\chi^{2}\left(\mathrm{MPa}^{2}\right)$} \\
\hline & & & $\mathrm{C}_{\mathrm{R}}(\mathrm{MPa})$ & $\lambda_{\mathrm{L}}(-)$ & \\
\hline \multirow[t]{9}{*}{80} & 5 & 5 & 0.051 & 25.87 & $2.80 \times 10^{-5}$ \\
\hline & & 10 & 0.052 & 18.66 & $3.90 \times 10^{-13}$ \\
\hline & & 15 & 0.056 & 12.74 & $5.04 \times 10^{-12}$ \\
\hline & 10 & 5 & 0.042 & 38.28 & $1.75 \times 10^{-2}$ \\
\hline & & 10 & 0.055 & 70.12 & $6.50 \times 10^{-3}$ \\
\hline & & 15 & 0.047 & 10.27 & $1.34 \times 10^{-5}$ \\
\hline & 15 & 5 & 0.041 & 10.80 & $8.34 \times 10^{-13}$ \\
\hline & & 10 & 0.055 & 32.17 & $2.30 \times 10^{-3}$ \\
\hline & & 15 & 0.050 & 16.48 & $3.02 \times 10^{-5}$ \\
\hline \multirow[t]{8}{*}{100} & 5 & 5 & 0.053 & 15.57 & $1.74 \times 10^{-12}$ \\
\hline & & 10 & 0.061 & 11.86 & $9.22 \times 10^{-11}$ \\
\hline & 10 & 5 & 0.079 & 11.68 & $6.87 \times 10^{-11}$ \\
\hline & & 10 & 0.055 & 15.03 & $5.27 \times 10^{-11}$ \\
\hline & & 15 & 0.060 & 15.95 & $9.61 \times 10^{-13}$ \\
\hline & 15 & 5 & 0.063 & 15.15 & $1.89 \times 10^{-12}$ \\
\hline & & 10 & 0.063 & 14.88 & $5.23 \times 10^{-11}$ \\
\hline & & 15 & 0.065 & 18.79 & $8.65 \times 10^{-13}$ \\
\hline 120 & 10 & 5 & 0.065 & 17.05 & $3.72 \times 10^{-12}$ \\
\hline
\end{tabular}

In indents, the vulcanization using the combined infrared and hot-air heating at the lower vulcanized temperature provided high elasticity (represented by the rubber modulus) and strength (represented by the maximum Cauchy stress in the axial direction) of rubber glove as well as the vulcanization using the only infrared heating at the higher vulcanized temperature. Furthermore, at the same vulcanized duration, the optimized condition of vulcanized rubber glove using the combined infrared and hot-air heating was found to be shorter in the distance between infrared heater and rubber glove than that using the only infrared heating.

From the Cauchy stress-stretch relationships (Fig. 3) of 6 vulcanized conditions, it can be revealed that the most ductile rubber glove was found at the vulcanized condition of $80^{\circ} \mathrm{C}, 5 \mathrm{~cm}$ and $5 \mathrm{~min}$ with the maximum stretch of 11.54. The most elastic rubber glove was found at the vulcanized condition of $80^{\circ} \mathrm{C}, 10 \mathrm{~cm}$ and 5 min with the smallest $C_{R}$ of $0.042 \mathrm{MPa}$ and the strongest rubber glove was found at the vulcanized condition of $80^{\circ} \mathrm{C}, 10 \mathrm{~cm}$ and $15 \mathrm{~min}$ with the maximum Cauchy stress of $7.35 \mathrm{MPa}$. Regarding the temperature distribution and the material parameters, the optimized condition of vulcanized rubber glove was then found at $80^{\circ} \mathrm{C}, 10 \mathrm{~cm}$ and $15 \mathrm{~min}$ which the standard deviation of temperature distribution was found to be equal to $3.53^{\circ} \mathrm{C}$. The material parameter set of $C_{R}$ and $\lambda_{L}$ was respectively found to be equal to $0.047 \mathrm{MPa}$ and 10.27 and the maximum Cauchy stress was found to be equal to $7.35 \mathrm{MPa}$.
Finally, as shown in Fig. 4, the capture images of the Cauchy stress distributions were illustrated on the deformed dumbbell-shaped test samples. The stress distributions were assumed to be null at the ends of the dumbbell-shaped test sample and be increased nonlinearly from the end towards the middle of the sample. Therefore, the maximal stresses of each deformed dumbbell-shaped test sample were found at the middle (line of symmetry about $\mathrm{x}$-axis).

However, there are limitations associated with the experimental constraint and assumption, i.e., the velocity of circulated hot air must be varied to determine the optimized value and the rubber should be treated as viscoelastic material. The rubber behavior could be considered to include the viscoelastic properties. Therefore, the viscoelastic properties will be studied in the future by investigating both loading and unloading conditions to select the suitable viscoelastic model and then determine the viscoelastic parameters.

\section{CONCLUSION}

In this study, we investigated the Cauchy stressstretch relationships of rubber gloves vulcanized using combined infrared and hot-air heating with different vulcanized conditions. The material parameter sets were determined using a parameter estimation technique. The Cauchy stress distributions can be successfully predicted 
using the Langevin (Arruda and Boyce) 8-chain model with our optimized material parameters. In summary, the rubber gloves vulcanized using our method could be practically used based on ASTM D 412 testing standard. The Cauchy stress-stretch relationships were determined in detail. The stress-strain behavior could be captured in this present work.

\section{ACKNOWLEDGEMENT}

This study was supported in part by the Small Project on Rubber (SPR) under the Thailand Research Fund (TRF) and the Faculty of Engineering and AgroIndustry, Maejo University, Chiang Mai, Thailand. The authors also wish to express sincere appreciation to Thitamorn Kuenpanya and Wongduen Poonsawas for all additional helpful data.

\section{REFERENCES}

Ali, A., M. Hosseini and B.B. Sahari, 2010. A review of constitutive models for rubber-like materials. Am. J. Eng. Applied Sci., 3: 232-239. DOI: 10.3844/ajeassp.2010.232.239

Arruda, E.M. and M.C. Boyce, 1993. A threedimensional constitutive model for the large stretch behaviour of rubber elastic materials. J. Mechan. Phys. Solids, 41: 389-412. DOI: 10.1016/0022-5096 (93)90013-6.

Bideau, P.L., J.P. Ploteau, P. Dutournie and P. Glouannec, 2009. Experimental and modelling study of superficial elastomer vulcanization by short wave infrared radiation. Int. J. Thermal Sci., 48: 573-582. DOI: 10.1016/j.ijther-malsci.2008.03.016

Boyce, M.C. and E.M. Arruda, 2000. Constitutive models of rubber elasticity: A review. Rubber Chemistry Technol., 73: 504-523. DOI: 10.5254/1.3547602.

Clark, D.E. and W.H. Sutton, 1996. Microwave processing of materials. Annual Rev. Mater. Sci., 26: 299-331. DOI: 10.1146/annurev.ms.26.080196.001503.

Clausen, A.H., M.T. Hovden, M.P. Loria, T. Berstad and O.S. Hopperstad, 2010. A constitutive model for thermoplastics with some applications. Proceedings of the IMPLAST, Providence, Rhode Island, USA.

Dongbang, W. and A. Matthujak, 2013. Anchovy drying using infrared radiation. Am. J. Applied Sci., 10: 353-360. DOI: 10.3844/ajassp.2013.353.360
Guo, Z. and L.J. Sluys, 2006. Application of a new constitutive model for the description of rubberlike materials under monotonic loading. Int. J. Solids Struct., 43: 2799-2819. DOI: 10.1016/j.ijsolstr.2005.06.026.

Humphrey, J.D. and S.L. Delange, 2004. An Introduction to Biomechanics: Solids and Fluids, Analysis and Design. Springer-Verlag, New York, ISBN: 0387402497, pp: 283.

Lakhal, W., S. Trabelsi, E. Sediki and M. Moussa, 2009. Combined thermal radiation and mixed convection in an inclined circular duct. Am. J. Eng. Applied Sci., 2: 590-602. DOI: 10.3844/ajeassp.2009.590.602

Makuuchi, K., F. Yoshii, I. Ishigaki, K. Tsushima and M. Mori et al., 1990. Development of rubber gloves by radiation vulcanization. Radiation Phys. Chemistry, 35: 154-157. DOI: 10.1016/1359-0197(90)90075-S.

Marckmann, G. and E. Verron, 2006. Comparison of hyperelastic models for rubberlike materials. Rubber Chemistry Technol., 79: 835-858. DOI: 10.5254/1.3547969

Ogden, R.W., G. Saccomandi and I. Sgura, 2004. Fitting hyperelastic model to experimental data. Comput. Mech., 34: 484-502. DOI: 10.1007/s00466-0040593-y.

Qi, H.J. and M.C. Boyce, 2004. Constitutive model for stretch-induced softening of the stress-stretch behavior of elastomeric materials. J. Mechan. Phys. Solids, 52: 2187-2206. DOI: 10.1016/j.jmps.2004.04.008.

Sasso, M.G., G. Palmieri, G. Chiappini and D. Amodio, 2008. Characterization of hyperelastic rubber-like materials by biaxial and uniaxial stretching tests based on optical methods. Polymer Testing, 27: 9951004. DOI: 10.1016/j.poly-mertesting.2008.09.001.

Zhang, B.L., M. Chen and N.J. Ao, 2004. Study on hot air aging and thermooxidative degradation of peroxide prevulcanized natural rubber latex film. J. Applied Polymer Sci., 92: 3196-3200. DOI: 10.1002/app.20313 